\title{
Improved Electro- and Photocatalytic Water Reduction by Confined Cobalt Catalysts in Streptavidin
}

\author{
Arnau Call, ${ }^{\dagger, * \odot}$ Carla Casadevall, ${ }^{\dagger, \dagger}$ Adrian Romero-Rivera, ${ }^{\S}$ Vlad Martin-Diaconescu, ${ }^{\dagger}$ \\ Dayn J. Sommer, ${ }^{\|}$Sílvia Osuna, ${ }^{\S, \perp}$ Giovanna Ghirlanda, ${ }^{*}, \|$ and Julio Lloret-Fillol ${ }^{*}, \forall, \perp \odot$
}
${ }^{\dagger}$ Institute of Chemical Research of Catalonia (ICIQ), The Barcelona Institute of Science and Technology, Avinguda Països Catalans 16, 43007 Tarragona, Spain
${ }^{\S}$ Institut de Química Computacional i Catàlisi (IQCC) and Departament de Química, Universitat de Girona, Carrer Maria Aurèlia Capmany 69, 17003 Girona, Spain
"School of Molecular Sciences, Arizona State University, Tempe, Arizona 85287-1604, United States
${ }^{\perp}$ Catalan Institution for Research and Advanced Studies (ICREA), Passeig Lluïs Companys, 23, 08010, Barcelona, Spain

\section{Supporting Information}

ABSTRACT: Incorporation of biotinylated aminopyridine cobalt complexes derived from the triazacyclononane scaffold into the streptavidin protein leads to formation of artificial metalloenzymes for water reduction to hydrogen. The synthesized artificial metalloenzymes have lower overpotential (at the half-peak up to $100 \mathrm{mV}$ ) and higher photocatalytic hydrogen evolution activity (up to 14and 10-fold increase in TOF and TON, respectively, at $\mathrm{pH} 12.5$ ) than the free biotinylated cobalt complexes. ${ }^{1} \mathrm{H}-\mathrm{NMR}, \mathrm{EPR}$ and XAS highlight the presence of the metal complexes upon supramolecular attachment to the streptavidin. $\mathrm{pH}$ dependent catalytic studies and molecular dynamics (MD) simulations suggest that the increase in the catalytic activity could be induced by the protein residues positioned close to the metal centers. These findings illustrate the ability of the

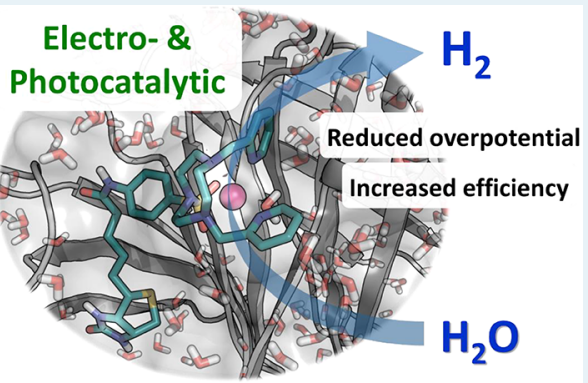
biotin-streptavidin technology to produce artificial metalloproteins for photo- and electrocatalytic hydrogen evolution reaction. KEYWORDS: water reduction to hydrogen, photocatalysis, electrocatalysis, cobalt complexes, streptavidin-biotin

\section{INTRODUCTION}

Among the possible alternative fuels, molecular hydrogen obtained from light-driven water splitting is ideal from an environmental point of view. ${ }^{1}$ However, sustainable generation of hydrogen is extraordinarily challenging and requires a profound understanding of the different reactions involved. In this context, rational design of catalytic systems serves as a tool to interrogate strategies to maximize efficiency and robustness as well as to unravel the mechanistic details. ${ }^{2}$ Likewise, nature has served as inspiration by studying and mimicking hydrogenase enzymes, which reversibly catalyze the reduction of protons to molecular hydrogen with high efficiency (turnover frequencies of up to $21000 \mathrm{~s}^{-1}$ ). ${ }^{3}$

The high activity of hydrogenases is ascribed in part to the control of the geometry of the active site, the second coordination sphere, and the protection of the catalytic center. ${ }^{4}$ However, their characterization and further development for practical applications is a demanding task. Conversely, catalysts active in $\mathrm{H}_{2}$ evolution based on metal complexes are tunable $e^{5}$ for improving the catalytic activity and overpotentials and increasing the oxygen tolerance. However, most organometallic catalysts are only efficient with strong acids in organic solvents or they are not sufficiently robust in water to be catalytically active. Moreover, control of the second coordination sphere suffers from significant synthetic challenges, although it is crucial to improve the TOF. ${ }^{6,7}$

In this regard, hybrid natural-artificial systems could serve as testing grounds to study the effect of protein scaffold encapsulation and second-sphere interactions in the catalytic performance of coordination complexes. ${ }^{3 \mathrm{~b}, 8}$ Several artificial protein-catalysts hybrids have been developed either by assembling synthetic catalysts into the protein pocket ${ }^{9}$ or by creating biomimetic systems made by metal substitution and/ or mutation. ${ }^{10}$ One of the most convenient synthetic approaches builds on supramolecular host-guest interactions, for example, using streptavidin (SA) as a host protein and exploiting its high affinity for biotin (also known as vitamin B7 or vitamin $\mathrm{H}$ ). SA binds biotin with one of the strongest noncovalent interactions known in nature (dissociation constant $\left(K_{\mathrm{d}}\right)$ on the order of $\left.\sim 10^{-14}\right)$, ensuring quantitative incorporation of biotinylated molecules. ${ }^{11}$ In addition, the biotin-SA complex is resistant to organic solvent, temperature, and $\mathrm{pH}$. On the basis of a concept first reported by Whitesides ${ }^{12}$ and further developed by the Ward group, the biotin-SA technology has been applied to create artificial

Received: December 13, 2018

Revised: April 25, 2019

Published: May 13, 2019 
metalloenzymes for a broad variety of catalytic applications. ${ }^{13}$ Very recently, this strategy has also been explored in hydrogen evolution catalysis. It has been observed that the resulting artificial hydrogenases are able to drive $\mathrm{H}_{2}$ evolution when using $\left[\mathrm{Ru}(\mathrm{bpy})_{3}\right] \mathrm{Cl}_{2}$ as a photosensitizer and ascorbate as a sacrificial electron donor, albeit with no significant improvement over the "naked" catalyst. ${ }^{14}$

We recently described a new family of robust, well-defined, and highly tunable aminopyridine cobalt complexes derived from the triazacyclononane (tacn) scaffold for the electro- and photocatalytic $\mathrm{H}_{2}$ evolution in water. ${ }^{15}$ In view of these unique properties and inspired by the previous studies, here we study the encapsulation of two new biotinylated aminopyridine cobalt complexes in SA for photo- and electrocatalytic $\mathrm{H}_{2}$ production. We found that encapsulation increases the activity significantly under both sets of conditions. Detailed electroand photochemical $\mathrm{pH}$-dependent hydrogen evolution studies and molecular dynamics (MD) simulations have been performed to elucidate the enhanced catalytic activity observed.

\section{RESULTS AND DISCUSSION}

We synthesized and studied two new biotinylated cobalt complexes (Cat ${ }^{\text {Bio }}$ ) based on the 1,4-di(picolyl)-1,4,7triazacyclononane $\left({ }^{\mathrm{H}} \mathrm{Py}_{2}\right.$ tacn) moiety by employing two different rigid spacer groups for the covalent bond between the biotin and the catalytic center (Figure 1) $)^{15 a}$ in order to investigate the catalytic activity of the cobalt center when positioned inside the protein pocket. ${ }^{13 f, 16}$ The biotin moiety was covalently attached to the tacn backbone either via the secondary nitrogen atom on the tacn $\left({ }^{B i o} \mathbf{P y}_{2}\right.$ tacn $)$ or via a free amine on the spacer group directly linked to the tacn ( ${ }^{\text {Bio-SP }} \mathbf{P y}_{2}$ tacn) through reaction with biotin $N$-hydroxysuccinimide active ester (NHS-biotin) (Scheme S1).

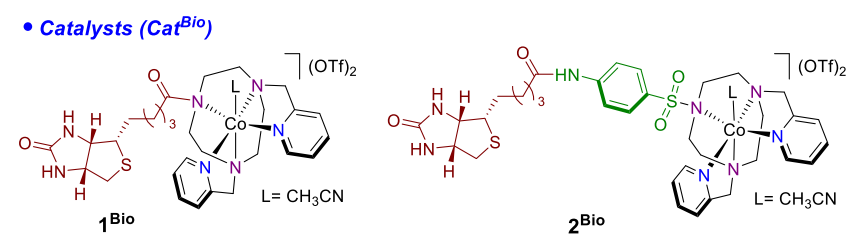

- Formation of metalloenzymes

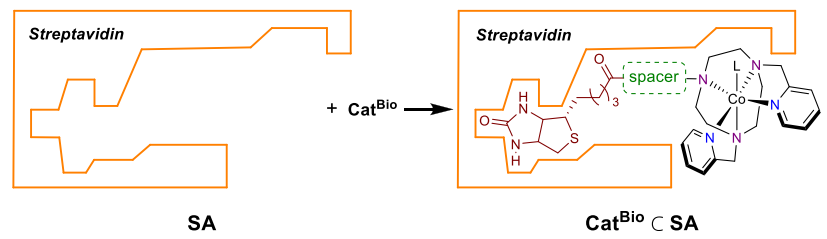

Figure 1. Biotinylated cobalt complexes and artificial metalloenzymes employed in this work.

The biotin-functionalized aminopyridine ligands and complexes $\left[\mathrm{Co}\left({ }^{\text {Bio }} \mathbf{P y}_{2}\right.\right.$ tacn $\left.)(\mathrm{MeCN})\right](\mathrm{OTf})_{2}\left(\mathbf{1}^{\mathbf{B i o}}\right)$ and $[\mathrm{Co}-$ $\left({ }^{\text {Bio-SP }} \mathbf{P y}_{2}\right.$ tacn $\left.)(\mathrm{MeCN})\right](\mathrm{OTf})_{2} \quad\left(\mathbf{2}^{\text {Bio }}\right)$ (Figure 1) were synthetized adapting a general procedure described in the literature (sections S.1.3 and 1.4). ${ }^{15 a, 17}$ The homologous nonbiotinylated $\left[\mathrm{Co}\left({ }^{\text {Amide }} \mathbf{P y}_{2}\right.\right.$ tacn $\left.)(\mathrm{MeCN})\right](\mathrm{OTf})_{2} \quad\left(\mathbf{1}^{\text {Amide }}\right)$ and $\left[\mathrm{Co}\left({ }^{\text {Amide-SP }} \mathbf{P y}_{2}\right.\right.$ tacn $\left.)(\mathrm{MeCN})\right](\mathrm{OTf})_{2}\left(\mathbf{2}^{\text {Amide }}\right)$ complexes were also synthesized with the aim to study how the absence of biotin affects their behavior (Scheme S1). The synthesis of the ligands Amide ${ } y_{2}$ tacn and ${ }^{A m i d e-S P} \mathbf{P y}_{2}$ tacn was carried out by acylating the free nitrogen atoms of ${ }^{\mathrm{H}} \mathbf{P y}_{2}$ tacn and ${ }^{\mathrm{NH} 2-S P} \mathbf{P y}_{2}$ tacn, respectively (section S.1.3). ${ }^{1} \mathrm{H}$ NMR spectroscopy, high-resolution electrospray ionization mass spectrometry (HR-MS-ESI), magnetic measurements, and elemental analysis confirm formation of $\mathrm{d}^{7}$ high-spin $(S=3 / 2) \mathrm{Co}^{\mathrm{II}}$ complexes (Figures $\mathrm{S} 1-\mathrm{S} 7)$. The cyclic voltammogram $(\mathrm{CV})$ of $\mathbf{1}^{\text {Bio }}$ and $\mathbf{1}^{\text {Amide }}$ in $\mathrm{CH}_{3} \mathrm{CN}$ shows a reversible peak ascribable to the $\mathrm{Co}^{\mathrm{II} / \mathrm{I}}$ couple at $-1.09 \mathrm{~V}$ (all redox processes are reported vs SCE unless otherwise notified) (Figures S10 and S12). Moreover, the reduction potential for the $\mathrm{Co}^{\mathrm{II} / \mathrm{I}}$ transition in $2^{\mathrm{Bio}}(-1.06 \mathrm{~V})$ is close to that of $2^{\text {Amide }}(-1.15$ V) (Figures S11 and S13). We note that complex $2^{\text {Bio }}$ exhibits an additional irreversible wave at $-0.71 \mathrm{~V}$, which can be attributed to reduction of the biotin moiety since it is also observed in the CV of the free ${ }^{\text {Bio-SP }} \mathbf{P y}_{2}$ tacn ligand and in the biotin (Figures S14-S17).

Incorporation of $\mathbf{1}^{\mathrm{Bio}}$ and $\mathbf{2}^{\mathrm{Bio}}$ into $\mathrm{SA}$ is quantitative, as indicated by the HABA (2-(4'-hydroxyazobenzene)benzoic acid) displacement assay. ${ }^{16}$ The linear profile of the HABA displacement by the biotinylated complexes indicates that their affinity for SA is similar to previously reported systems and in the range of that obtained with D-biotin (i.e., $>10^{10} \mathrm{M}^{-1}$, section S.1.5). ${ }^{16}$ The stoichiometry of the complex incorporated in the synthesized and isolated metalloenzymes $\mathbf{1}^{\text {Bio }} \mathbf{C ~ S A}$ and $2^{\text {Bio }}$ C SA was evaluated by measuring the Co concentration by ICP-MS and the protein concentration by UV-vis. These results are in concordance with previous reports, indicating saturation of the binding sites of the SA employed ( $S A$ is a tetramer containing a binding site per unit of monomer). Moreover, the paramagnetic ${ }^{1} \mathrm{H}$ NMR studies performed with free $\mathrm{SA}, \mathbf{2}^{\mathrm{Bio}}$, and $\mathbf{2}^{\mathrm{Bio}} \mathrm{C}$ SA indicate that the main proton resonance features of the cobalt complex are present with slight modifications after encapsulation into the SA and that some of the ${ }^{1} \mathrm{H}$ NMR features of the SA protein are also altered in the $\mathbf{2}^{\text {Bio }} \mathbf{C}$ SA sample, consistent with the supramolecular assembly (Figures S22-S25).

We also studied cobalt K-edge X-ray absorption spectroscopy (XAS) and EPR to provide information about the electronic and geometric structure of the metal coordination environment. The Co K-edge XAS spectra of $\mathbf{2}^{\text {Bio }}$ and $\mathbf{2}^{\text {Bio }} \mathbf{C}$ SA have a comparable profile, suggesting a similar coordination environment and oxidation state. The rising edges centered around $7719.3 \mathrm{eV}$ are consistent with a Co $\mathrm{Co}^{\mathrm{II}}$ center (Figure S26) ${ }^{18}$ Furthermore, the intensity of the pre-edges at 7710.4 $\mathrm{eV}$, of 0.06 normalized units, suggests a centrosymmetric pseudo-octahedral environment. ${ }^{18 \mathrm{a}}$ This is further supported by EPR experiments of $2^{\text {Bio }}$ and $2^{\text {Bio }} \mathbf{C}$ SA, which at liquid nitrogen temperatures show low-spin Co ${ }^{\mathrm{II}}$ signals with $g_{x}$ and $g_{y}$ values centered around a $g$ of 2.2 and $g_{z}$ values approaching 2.0, similar to previously reported values for elongated distorted pseudo-octahedral Co ${ }^{\mathrm{II}}$ complexes (Figure S27.B). ${ }^{6,19}$ On the other hand, the EPR spectra of $\mathbf{1}^{\text {Bio }}$ and $\mathbf{1}^{\text {Bio }} \mathbf{C}$ SA suggest an axially compressed pseudo-octahedral environment at the $\mathrm{Co}^{\mathrm{II}}$ center with $g_{z}$ values centered around a $g$ of 2.3 and $g_{x}$ and $g_{y}$ values close to 2.0 (Figure S27.A). ${ }^{6,19}$ At $15 \mathrm{~K}$ the EPR spectra are more informative. The basic EPR features observed in the $\left[\mathrm{Co}(\mathrm{OTf})\left({ }^{\mathrm{Ts}} \mathbf{P y}_{2}\right.\right.$ tacn $\left.)\right](\mathrm{OTf})(\mathbf{2}),\left[\mathrm{Co}(\mathrm{Cl})\left({ }^{\mathrm{Ts}} \mathbf{P y}_{2} \mathbf{t a c n}\right)\right](\mathrm{Cl})$ $2 \mathrm{Cl}, \mathbf{1}^{\mathrm{Bio}}$ and $2^{\mathrm{Bio}}$ series guide one to understand the EPR of $\mathbf{1}^{\text {Bio }} \mathbf{C ~ S A}$ and $\mathbf{2}^{\text {Bio }} \mathbf{C ~ S A}$ (Table S2). Interestingly, while the EPR spectrum of $2^{\text {Bio }} \mathbf{C ~ S A}$ is similar to that of $2^{\mathrm{Bio}}$, in the case of $\mathbf{1}^{\text {Bio }} \mathbf{C ~ S A}$ it is essentially different than $\mathbf{1}^{\text {Bio }}$. The EPR spectrum of $2^{\text {Bio }}$ C SA recorded at $15 \mathrm{~K}$ presents three 
different Co center environments as for $\mathbf{2}^{\text {Bio }}$ (Figure S33). The predominant one corresponds to a $\mathrm{Co}^{\mathrm{II}}$ high-spin center $(S=$ $3 / 2$ ), and two minor signals can be assigned to low-spin $\mathrm{Co}^{\mathrm{II}}$ centers coordinated to a different sixth ligand $\left(\mathrm{CH}_{3} \mathrm{CN}\right.$ and $\mathrm{H}_{2} \mathrm{O}$ ). In contrast, the main feature in the EPR spectrum of $\mathbf{1}^{\mathrm{Bio}} \mathbf{C}$ SA correspond to the rhombic signal with $g$ values centered at 2.37, 2.07, and 2.03, which is in agreement with coordination of a water molecule. This correlates with the fact that the cobalt complex in $\mathbf{1}^{\mathrm{Bio}} \mathbf{C ~ S A}$ is more internalized into the protein cavity as judged by the molecular dynamics (MD) simulations (dicussed below). Therefore, the presence of mainly a low-spin $\mathrm{Co}^{\mathrm{II}}$ rhombic signal may suggest that the protein pocket environment may regulate the binding ligand at the metal center. In the case of the $2^{\text {Bio }}$ C SA, MD simulations show that the cobalt complex is exposed to the protein surface, but it is much more exposed to the reaction media than $\mathbf{1}^{\mathrm{Bio}} \mathrm{C}$ SA. For both series of complexes the XAS and EPR spectroscopic data indicate only minor electronic and geometric environment modification of the $\mathrm{Cat}^{\mathrm{Bio}}$ after inclusion into the SA protein. Lastly, incorporation of the cobalt catalyst proceeds, conserving the SA secondary structure, as assessed by CD spectroscopy (Figure S21).

We compared the catalytic activity of these artificial metalloenzymes with the naked biotinylated cobalt complexes $\mathbf{1}^{\mathrm{Bio}}$ and $\mathbf{2}^{\mathrm{Bio}}$ in the electrochemical reduction of water to $\mathrm{H}_{2}$. The electrochemical measurements were performed at $\mathrm{pH}$ ranging from 3.5 to 6 (citrate $/ \mathrm{NaCl}$ buffer, $100 \mathrm{mM}$ ). At $\mathrm{pH}$ 3.5 the $\mathrm{CV}$ of $\mathbf{1}^{\text {Bio }}$ showed a high current intensity irreversible peak with an onset potential at $-1.21 \mathrm{~V}$ and a maximum at $-1.36 \mathrm{~V}$ (overpotential $(\eta)=0.78 \mathrm{~V})^{20}$ (Figure 2A, black trace), indicative of a catalytic process. Under the same conditions, complex $\mathbf{2}^{\text {Bio }}$ showed similar electrochemical features but shifted to a more negative potential (onset potential about $-1.23 \mathrm{~V}$ and a maximum at $-1.47 \mathrm{~V}, \eta=0.79$ $\mathrm{V}$, Figure 2C). The electrocatalytic wave in both complexes $\left(\mathbf{1}^{\text {Bio }}\right.$ and $\left.\mathbf{2}^{\text {Bio }}\right)$ displays a $\mathrm{pH}$ dependence. The currents appear to follow a nonstandard behavior in the case of $\mathbf{2}^{\text {Bio }}$ with a change in slope as the potential is increased. The electrocatalytic peak current $\left(i_{c}\right)$ increases with the proton concentration (Figures S35 and S36), suggesting that the rate-determining step of the catalytic process relies on a proton transfer from water. ${ }^{21}$ The onset, the peak potential for proton reduction $\left(E_{\mathrm{p}}\right)$, and the half peak $\left(E_{1 / 2}\right)$ of $\mathbf{1}^{\text {Bio }}$ shift toward less negative potentials when increasing the proton concentration, following a PCET (proton-coupled electron transfer) reaction (Figure 2 and Figure S46). ${ }^{22}$ The Nernstian response was found to be $-37 \mathrm{mV}$ per $\mathrm{pH}$ unit (Figure 2B), close to expected for a 2-electron and 1-proton reduction process $(-30$ $\mathrm{mV}$ per $\mathrm{pH}$ ). This value is qualitatively similar to the $-26 \mathrm{mV}$ per $\mathrm{pH}$ unit reported for a $\mathrm{Co}(\mathrm{Py} 5)$ system $^{21 \mathrm{~b}}$ or to the -24 $\mathrm{mV}$ per $\mathrm{pH}$ unit observed in cobalt diamine systems. ${ }^{21 a}$ Complex $2^{\text {Bio }}$ reveals only a minor dependence of the $E_{\mathrm{p}}$ and onset potential with the $\mathrm{pH}$ (Figure 2D). The molecular behavior of $\mathbf{1}^{\text {Bio }}$ and $\mathbf{2}^{\text {Bio }}$ was confirmed by rinsing tests (Figure S36), which indicates the absence of active species attached to the electrode surface. ${ }^{23}$ Furthermore, the catalytic current shows a first-order dependence on the catalyst concentration ${ }^{24}$ (Figure S37) similarly to what was observed for the parent complex 2 . $^{15 a}$

The electrochemical properties of $\mathrm{Cat}^{\mathrm{Bio}} \mathrm{C}$ SA were interrogated as a thin film, ${ }^{3 a, 9 c, 10 a, 25}$ prepared by drop casting over a glassy carbon electrode and carbon cloth (see sections S.1.7 and S.1.8), which yields an intense electrocatalytic wave
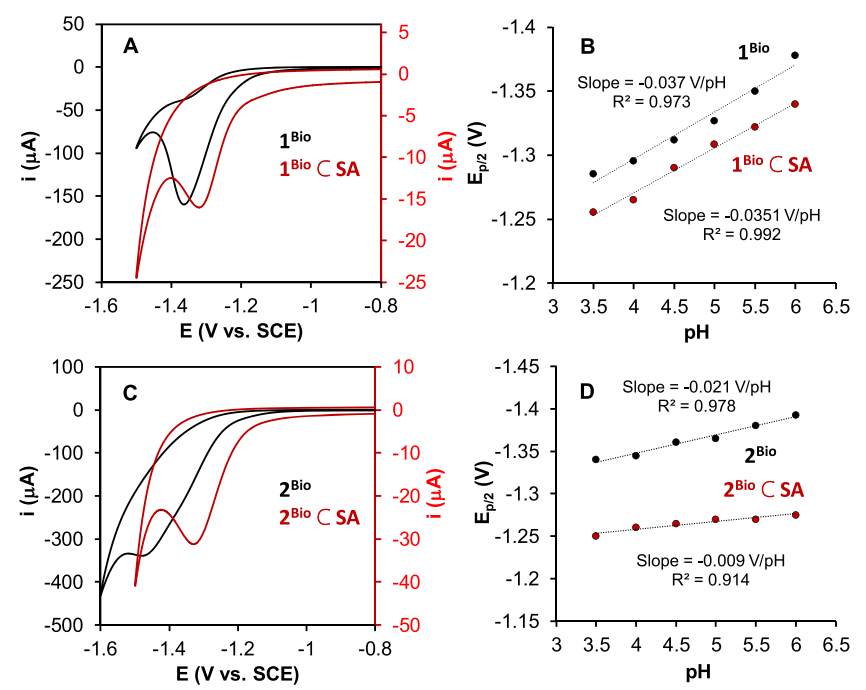

Figure 2. $\mathrm{CV}$ of (A) $\mathbf{1}^{\text {Bio }}\left(1 \mathrm{mM}\right.$, black trace) and $\mathbf{1}^{\text {Bio }} \mathrm{C}$ SA (thin film, red trace) and (C) $\mathbf{2}^{\text {Bio }}\left(1 \mathrm{mM}\right.$, black trace) and $\mathbf{2}^{\text {Bio }} \mathrm{C} \mathrm{SA}$ (thin film, red trace) (see section S.1.7 for detailed experimental conditions). Plot of the half intensity of the catalytic peak potential $\left(E_{\mathrm{p}}\right)$ as a function of $\mathrm{pH}$ of $(\mathrm{B}) \mathbf{1}^{\mathrm{Bio}}(1 \mathrm{mM})$ and $\mathbf{1}^{\text {Bio }} \mathbf{C ~ S A}$ (thin film) and (D) $\mathbf{2}^{\text {Bio }}(1 \mathrm{mM})$ and $\mathbf{2}^{\text {Bio }} \mathrm{C} \mathrm{SA}$ (thin film).

(Figure S38). For comparison, we also analyzed and compared the $\mathrm{CV}$ of $\mathbf{2}^{\text {Bio }} \mathbf{C}$ SA $(73 \mu \mathrm{M})$ in solution, which gives similar results under the same experimental conditions (Figure S39). When the cathodic scan was performed in the presence of naked SA the observed current was negligible at this redox potential (Figure S38), indicating that the catalytic wave observed for $\mathbf{C a t}^{\text {Bio }} \mathbf{C}$ SA is due to the hosted $\mathbf{C a t}^{\mathrm{Bio}}$. The reduction potential of the reduction peak did not change with the amount of protein deposited on a carbon cloth electrode, suggesting that protein-protein interactions possible in the film do not interfere in the redox process (Figure S40). The catalytic activity of the $\mathrm{Cat}^{\mathrm{Bio}} \mathbf{C}$ SA adducts display a $\mathrm{pH}$ dependence (Figures S42 and S43) comparable to that obtained with the $\mathbf{C a t}^{\mathrm{Bio}}$ and Cat ${ }^{\mathrm{Amide}}$ catalysts (Figures S35, S36, S44-S48, S55, and S56). A clear shift in the redox potential of the catalytic value $\left(\Delta E_{\mathrm{p}}, \Delta E_{\mathrm{p} / 2}\right.$, and onset potential) was observed when the $\mathbf{C a t}^{\mathrm{B} \text { io }}$ were incorporated into the host SA. The magnitude of the redox potential shift when the current intensity is one-half of the value regarding the current intensity at the maximum of the catalytic peak $\left(\Delta E_{\mathrm{p} / 2}\right)$ varies with the $\mathrm{pH}$ value and ranges between 20 and $30 \mathrm{mV}$ for $\mathbf{1}^{\text {Bio }}$ and $\mathbf{1}^{\text {Bio }} \mathbf{C ~ S A}$ (Figure $2 \mathrm{~B}$ ) and between 60 and $100 \mathrm{mV}$ for $\mathbf{2}^{\text {Bio }}$ and $\mathbf{2}^{\text {Bio }}$ C SA (Figure 2D) (Figures S44S46). This result is in sharp contrast with those previously reported for some artificial metalloenzymes based on cobalt complexes. ${ }^{9 c, 10 a, e}$ For instance, incorporating cobaloxime derivatives into the heme pocket of apo sperm-whale myoglobin results in a negative shift of about $100 \mathrm{mV}$, increasing the overpotential. ${ }^{9 \mathrm{c}}$ Conversely, the positive direction of the shift observed for our systems suggests beneficial interactions of the SA pocket with the catalyst (presumably the secondary coordination sphere) that reduces the water reduction overpotential. However, a direct comparison of current density is not straightforward since the protein concentration on the electrode is unknown.

To verify the formation of $\mathrm{H}_{2}$ we performed controlled potential electrolysis (CPE) at $-1.4 \mathrm{~V}$ during $3 \mathrm{~h}$ under static conditions for $\mathbf{2}^{\text {Bio }}$ and $2^{\text {Bio }}$ C SA (Figures S49-S51). In both 

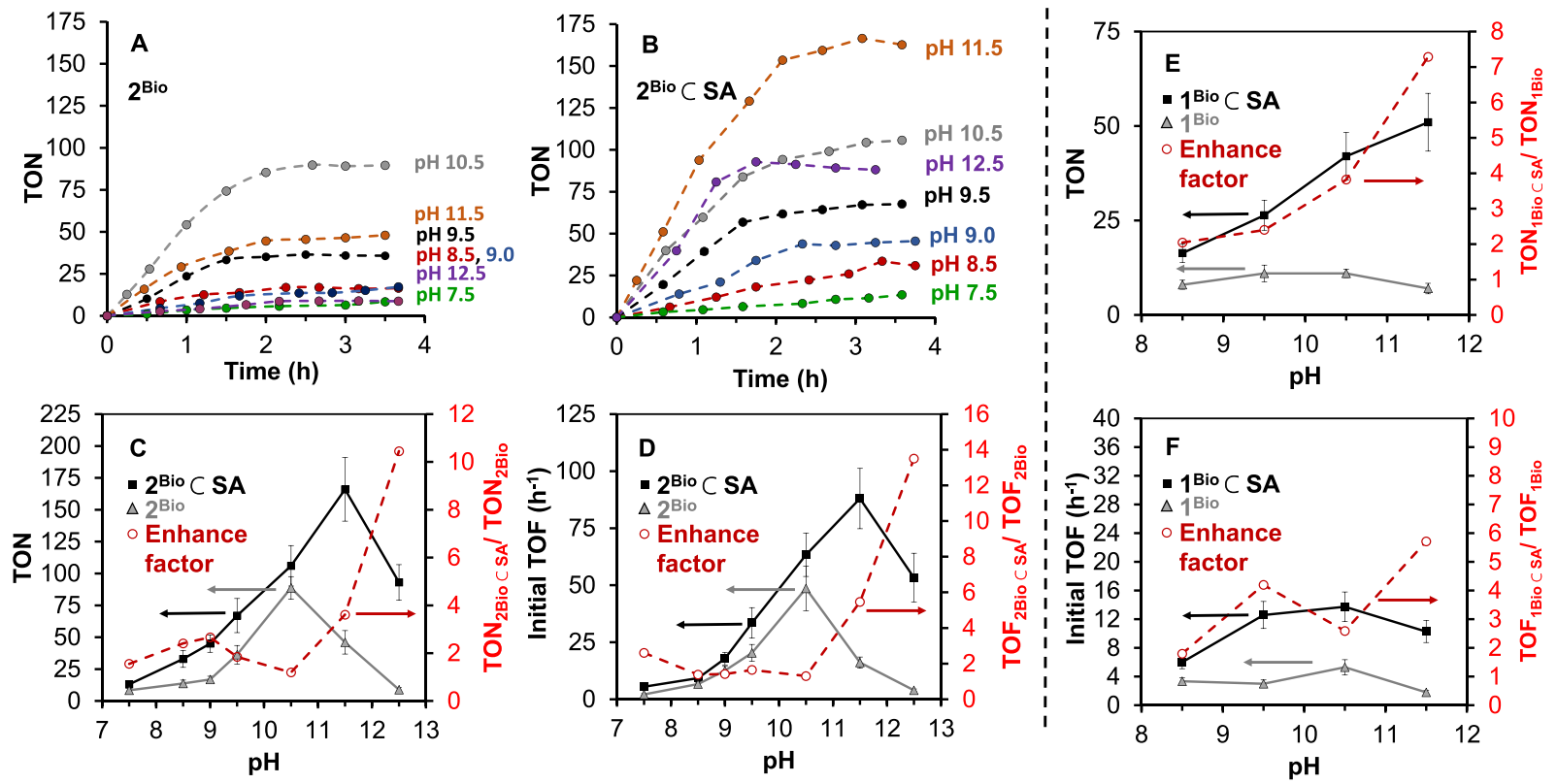

Figure 3. Photoinduced $\mathrm{H}_{2}$ production at different $\mathrm{pH}$ values for reaction of $\mathbf{C a t}^{\text {Bio }}$ and Cat $^{\text {Bio }} \mathbf{C ~ S A}(5 \mu \mathrm{M}$ in Co $), \mathbf{P S}_{\text {Ir }}(250 \mu \mathrm{M})$, TEOA $(0.4 \mathrm{M})$ in $0.4 \mathrm{~mL}$ of $\mathrm{CH}_{3} \mathrm{CN}: \mathrm{H}_{2} \mathrm{O}(3: 7 \mathrm{v} / \mathrm{v})$ containing phosphate buffer $(100 \mathrm{mM})$ and $\mathrm{NaCl}(100 \mathrm{mM})$ after $4 \mathrm{~h}$ irradiation $\left(1100 \mathrm{~W} \cdot \mathrm{m}^{-2}, \lambda>400 \mathrm{~nm}\right)$. Time traces of $\mathrm{H}_{2}$ evolved using (A) $\mathbf{2}^{\text {Bio }}$ and (B) $\mathbf{2}^{\text {Bio }}$ C SA. (C) TON for $\mathbf{2}^{\text {Bio }}$ (gray) and $2^{\text {Bio }} \mathbf{C ~ S A}$ (black) and TON TBio C SA TON ${ }_{2 B i o}$ (red). (D) Initial TOF $\left(\mathrm{h}^{-1}\right)$ for $\mathbf{2}^{\text {Bio }}$ (gray), $\mathbf{2}^{\text {Bio }} \mathbf{C ~ S A}$ (black), and $\mathrm{TOF}_{2 \mathrm{Bio} \mathrm{C} \mathrm{SA}} / \mathrm{TOF}_{2 \mathrm{Bio}}$ (red). (E) TON for $\mathbf{1}^{\text {Bio }}$ (gray) and $\mathbf{1}^{\text {Bio }} \mathbf{C ~ S A}$ (black) and $\mathrm{TON}_{1 \text { Bio C sA }} / \mathrm{TON}_{1 \text { Bio }}$ (red). (F) Initial TOF $\left(\mathrm{h}^{-1}\right)$ for $\mathbf{1}^{\text {Bio }}$ (gray), $\mathbf{1}^{\mathrm{Bio}} \mathbf{C ~ S A}$ (black), and $\mathrm{TOF}_{1 \text { Bio C SA }} / \mathrm{TOF}_{1 \text { Bio }}$ (red). Error bars are average of two duplicates.

cases $\mathrm{H}_{2}$ was detected by sampling the headspace of the electrochemical cell after the CPE and subjecting the sample to chromatographic analysis (gas chromatography-thermal conductivity detector, GC-TCD). In the case of $\mathbf{2}^{\text {Bio }} \mathbf{C ~ S A}$, after an initial current decrease it remains about constant for the rest of the experiment with good Faraday yield. In contrast, under the same CPE conditions, $2^{\text {Bio }}$ yields about 560 TON of $\mathrm{H}_{2}$ with good Faraday yield, but suffers a fast and intense activation process during the $\mathrm{CPE}$, leading to a higher current density (Figure S51). This is indicative of the formation of a more active species. A CV after the CPE with a clean GC electrode did not show any wave in the $\mathrm{CV}$ at the $\mathrm{Co}^{\mathrm{II} / \mathrm{I}}$ redox couple $\mathbf{2}^{\text {Bio }}$. In contrast, after $3 \mathrm{~h}$ of CPE the CV of the $\mathbf{2}^{\text {Bio }} \mathrm{C}$ SA solution presents a wave, although shifted and significantly reduced.

We hypothesized that the observed difference in activity between Cat ${ }^{\mathrm{Bio}}$ and $\mathrm{Cat}^{\mathrm{Bio}} \mathbf{C}$ SA is due to secondary sphere interactions with the protein scaffold. To rule out other possibilities, such as coordination of biotin to the cobalt center, we also studied the electrochemical behavior of model complexes $1^{\text {Amide }}$ and $2^{\text {Amide }}$. We found that $1^{\text {Amide }}$ and $2^{\text {Amide }}$ exhibit similar electrochemical behaviors $\left(\mathrm{Co}^{\mathrm{II} / \mathrm{I}}\right.$ redox couples and $\mathrm{pH}$ behavior) to the $\mathbf{C a t}^{\mathrm{Bio}}$ homologous complexes. In addition, the cyclic voltammograms of $\mathbf{1}^{\text {Amide }}$ and $2^{\text {Amide }}$ in $\mathrm{CH}_{3} \mathrm{CN}$ shows negligible changes upon addition of large amounts of esterified biotin (up to 20 equiv, biotin was esterified for solubility reasons, Figures S53 and S54). We also studied computationally (B3LYP-3D/6-31+G** level of theory) the possible coordination modes for the $\mathrm{N}, \mathrm{O}$, and $\mathrm{S}$ atoms of biotin to the cobalt center in oxidation states I and II. All optimized structures showed that intramolecular coordination of biotin to the cobalt center is largely endergonic. In addition, an exchange between a coordinated pyridine (or tacn backbone) and a $\mathrm{N}, \mathrm{O}$, or $\mathrm{S}$ atom of biotin is also highly endergonic (Figures S79-S81 and S84-S86). The bimolecular biotin interactions appear negligible as there is a linear correlation between the current intensity and the Cat ${ }^{\text {Bio }}$ concentration (vide supra). All of these observations together with the XAS, EPR and catalysis show no coordination of biotin to the cobalt center and indicate that the $\Delta E_{\mathrm{p}}$ observed between Cat $^{\text {Bio }}$ and Cat $^{\text {Bio }}$ C SA arises form second coordination sphere interactions between the catalytic center and the protein pocket.

We also investigated whether the catalytic activity of $\mathbf{1}^{\text {Bio }}$ and $2^{\text {Bio }}$ could be influenced by protein encapsulation in lightdriven $\mathrm{H}_{2}$ evolution. The catalytic activity of $2^{\text {Bio }}$ and $2^{\text {Bio }} \mathbf{C ~ S A}$ was studied by irradiation $\left(1100 \mathrm{~W} \cdot \mathrm{m}^{-2}\right.$ of visible light, $\lambda>$ $400 \mathrm{~nm}$ ) of a solution containing the catalysts $(5 \mu \mathrm{M})$, $\left[\operatorname{Ir}(\text { ppy })_{2}(\right.$ bpy $\left.)\right] \mathrm{PF}_{6} \quad\left(\mathbf{P S}_{\text {Ir }}\right) \quad(250 \mu \mathrm{M})$ and TEOA (0.4 $\mathrm{M}){ }^{26,15 a}$ Due to the low solubility of $\mathbf{P S}_{\mathrm{Ir}}$ in water, $30 \%$ in volume of $\mathrm{MeCN}$ was used as a cosolvent. We verified the stability of $\mathbf{2}^{\text {Bio }} \mathbf{C}$ SA by monitoring its secondary structure by $\mathrm{CD}$ at increasing concentrations of $\mathrm{CH}_{3} \mathrm{CN}$. No changes in the $\mathrm{CD}$ were observed up to $50 \%$ of cosolvent (Figures S57 and S58) nor in all of the $\mathrm{pH}$ range studied (Figures S59-S62).

Hydrogen evolution was monitored as a function of time by analysis of aliquots from the reaction cuvette headspace by gas chromatography at different $\mathrm{pH}$ values adjusted with phosphate buffer $(100 \mathrm{mM})$. The $\mathrm{pH}$ of the buffer solutions was measured and adjusted (when needed) after addition of TEOA using $\mathrm{NaOH}$ or $\mathrm{HCl}$. The catalytic activity of $\mathbf{2}^{\text {Bio }}$ raises from $\mathrm{pH} 7$ to a maximum at about $\mathrm{pH} 10.5$ (TON, 89; TOF, $49 \cdot \mathrm{h}^{-1}$; Figure 3$) .^{27}$ For $\mathbf{2}^{\text {Bio }} \mathbf{C ~ S A}$ the catalytic activity was higher than for $2^{\text {Bio }}$ at all $\mathrm{pH}$ values, and the maximum in catalytic activity changes from $\mathrm{pH} 10.5$ to 11.5 (Table S4). A $\mathrm{pH}$ bell-shaped profile is observed for the catalytic activity of both $2^{\text {Bio }}$ and $2^{\text {Bio }}$ C SA (Figure 3). This bell shape has been previously observed in photocatalytic systems such as $\mathrm{Ru} /$ ascorbate ${ }^{28}$ and fluorescein/ $/ \mathrm{Et}_{3} \mathrm{~N}$. $^{29}$ The stablished reason for this catalytic activity $\mathrm{pH}$ behavior is that at lower $\mathrm{pH}$ the 
effective electron donor concentration (TEOA) is reduced, while at higher $\mathrm{pH}$ values the catalytic activity decreases due to the lower concentration of protons available, resulting in the catalytic activity vs $\mathrm{pH}$ in a bell-shaped profile.

The difference in the catalytic activity between $2^{\text {Bio }}$ and $2^{\text {Bio }}$ C SA increases at higher $\mathrm{pH}$ values. At $\mathrm{pH} 12.5$ the catalytic activity of $2^{\text {Bio }}$ C SA is 10- and 14-fold higher in terms of TON and TOF, respectively, than the values obtained for $2^{\text {Bio }}$. Moreover, at $\mathrm{pH} 12.5$ the catalytic activity of $2^{\mathrm{Bio}}$ is negligible. This behavior may be rationalized if it is considered that the protein protects the cobalt center and alters the effective available protons for the metal protonation regarding the $\mathrm{pH}$. Nevertheless, this is a very complex system, and other possible contributions to the observed behavior cannot be discarded. It is important to note that protonation of the $\mathrm{Co}^{\mathrm{I}}$ species to give $\mathrm{Co}^{\mathrm{III}}-\mathrm{H}$ is thought to be the rate-limiting step in cobalt-based catalysts at basic $\mathrm{pH}$ values. ${ }^{15 a}$

Although $\mathbf{1}^{\text {Bio }}$ shows lower catalytic activity than $2^{\text {Bio }}$, the catalytic enhancement by the protein environment is also remarkable with an enhancement factor in TON at $\mathrm{pH} 11.5$ of 7.3 ( $1^{\text {Bio }}$ C SA) and 3.6 ( $2^{\text {Bio }}$ C SA), suggesting a better protecting effect by the protein pocket due to the absence of the spacer (Figure 3E and 3F and Table 1). Moreover, control

Table 1. Photocatalytic Activities of $2^{\text {Bio }}$ and $2^{\text {Bio }} \mathrm{C} \mathrm{SA}$ at $\mathrm{pH}$ $11.5^{a}$

$\begin{array}{llccc} & \mathbf{1}^{\text {Bio }} & \mathbf{1}^{\text {Bio }} \mathbf{C ~ S A} & \mathbf{2}^{\text {Bio }} & \mathbf{2}^{\text {Bio }} \mathbf{C ~ S A ~} \\ \text { TON } & 7 & 51 & 46 & 166 \\ \text { TON }_{\text {CatBio C SA }} / \text { TON }_{\text {CatBio }} & 7.3 & & 3.6 & \\ \text { TOF } & 1.8 & 10.3 & 16 & 88 \\ \text { TOF }_{\text {CatBio C SA }} / \text { TOF }_{\text {CatBio }} & 5.7 & & 5.5 & \end{array}$

${ }^{a}$ Cobalt catalyst $(5 \mu \mathrm{M}$ in Co $)$ PS $_{\text {Ir }}(250 \mu \mathrm{M})$, TEOA $(0.4 \mathrm{M})$ in 0.4 $\mathrm{mL}$ of $\mathrm{CH}_{3} \mathrm{CN}: \mathrm{H}_{2} \mathrm{O}(3: 7 \mathrm{v} / \mathrm{v})$ containing phosphate buffer (100 $\mathrm{mM})$ and $\mathrm{NaCl}(100 \mathrm{mM})(\mathrm{pH} 11.5)$ after $4 \mathrm{~h}$ irradiation $(1100 \mathrm{~W}$. $\left.\mathrm{m}^{-2}, \lambda>400 \mathrm{~nm}\right)$.

experiments performed generating the metalloenzyme in situ before catalysis (by mixing $2^{\text {Bio }}$ with SA $\sim 30 \mathrm{~min}$ before the catalysis) show the same catalytic activity as the presynthesized and purified $2^{\text {Bio }}$ C SA (Figure S65). In contrast, addition of SA to complex $2^{\text {Amide }}$ does not affect its photocatalytic activity (Figure S66), pointing toward an enhancement in the $\mathrm{H}_{2}$ production activity due to supramolecular interactions in $2^{\text {Bio }}$

C SA.

We also performed photochemical studies using $[\mathrm{Cu}$ (xantphos)(bathocuproine) $] \mathrm{PF}_{6}\left(\mathbf{P S}_{\mathrm{Cu}}\right.$ ) as photoredox catalyst and triethylamine $\left(\mathrm{Et}_{3} \mathrm{~N}\right)$ as electron donor in nonbuffered solutions (Figure 4). Under these catalytic conditions we found that the $\mathrm{H}_{2}$ evolution catalytic performance for the metalloproteins ( $\mathrm{Cat}^{\mathrm{Bio}} \mathbf{C ~ S A}$ ) is higher than for the $\mathrm{Cat}^{\mathrm{Bio}}$ in terms of both TOF and TON. Also, a remarkably higher quantity of hydrogen is formed than in the case of using the Ir photosensitizer $\left(\mathbf{P S}_{\text {Ir }}\right)$ in combination with TEOA.

We performed molecular dynamics (MD) simulations of streptavidin in complex with $\mathbf{1}^{\text {Bio }}$ and $\mathbf{2}^{\text {Bio }}$ to evaluate their binding modes and identify which residues play a crucial role on catalytic enhancement (see SI for computational details). These calculations do not capture protein-protein interactions and therefore are only relevant for isolated proteins such as the conditions employed in this study. Representative conformations sampled along the accumulated $750 \mathrm{~ns}$ of $\mathrm{MD}$ simulations (i.e., three replicas of $250 \mathrm{~ns}$ for each case) reveal

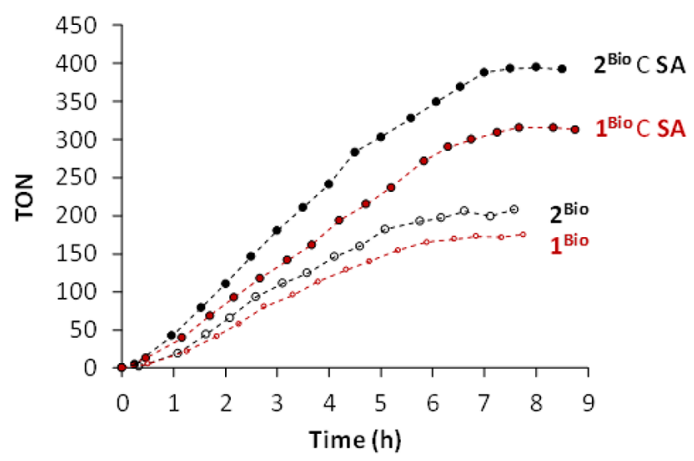

Figure 4. Traces of the photoinduced $\mathrm{H}_{2}$ production by (from top to bottom) $2^{\text {Bio }} \mathbf{C ~ S A ,} \mathbf{1}^{\text {Bio }} \mathbf{C ~ S A}, 2^{\text {Bio }}$, and $\mathbf{1}^{\text {Bio }}(5 \mu \mathrm{M})$ together with PS $_{\mathrm{Cu}}(250 \mu \mathrm{M}), \mathrm{Et}_{3} \mathrm{~N}(0.15 \mathrm{M})$ in $0.4 \mathrm{~mL}$ of $\mathrm{CH}_{3} \mathrm{CN}: \mathrm{H}_{2} \mathrm{O}(3: 7 \mathrm{v} / \mathrm{v})$ after $9 \mathrm{~h}$ irradiation $\left(1100 \mathrm{~W} \cdot \mathrm{m}^{-2}, \lambda>400 \mathrm{~nm}\right)$.

a high affinity of the protein toward $\mathbf{1}^{\mathrm{Bio}}$ and $\mathbf{2}^{\mathrm{Bio}}$. The presence of a spacer group between the biotin and the catalytic center in $2^{\text {Bio }}$ confers additional flexibility to the ligand, leading to two main different conformations (Figure S70). As in biotin-SA complex, tryptophan residues (Trp79, Trp92, Trp108) bind the ligand through $\mathrm{CH} \cdots \pi$ interactions (the mean distance between the center of mass of Trp108 and biotin rings is ca. $4.0 \AA$ for both $\mathbf{1}^{\text {Bio }}$ and $\mathbf{2}^{\text {Bio }}$, see Figure 5). ${ }^{30}$

To gain insights into the origin of the improvement in catalytic activity, we evaluated the conformational dynamics of the binding pocket in the presence of $\mathbf{1}^{\mathrm{Bio}}$ and $\mathbf{2}^{\mathrm{Bio}}$ (Figure 5). Polar residues around the cobalt complex together with the assistance of water could promote the catalysis. Both $\mathbf{1}^{\text {Bio }}$ and $2^{\text {Bio }}$ are exposed to several solvent molecules (ca. 3-5 waters in $\mathbf{1}^{\text {Bio }}$ and 2-4 waters in $\mathbf{2}^{\text {Bio }}$, Figures S69 and S72). In addition, many polar residues that could act as a proton donor or activate a water molecule to promote metal protonation are found close to the ligand (Figure 5). $1^{\text {Bio }}$ shows low flexibility during the MD simulations, sampling most of the time the same conformation, which positions the cobalt center near polar Ser112, Ser88, Glu51, and Asn49 residues (S67 and S68). In contrast, $\mathbf{2}^{\text {Bio }}$ is more flexible and adopts two different conformations during the MD simulations (the bend conformation highlighted in the square of Figure 5 and extended conformation of Mon3 in S34A). In the bend conformation, the metal center is situated close to polar residues Ser112 and Leu124 (Figure 5). For most of the simulation time the hydrophobic residue Leu124 in the bend conformation is near the metal center (Figures 5 and S71), suggesting that this residue could be mutated to enhance activity. In contrast, in the extended conformation, the metal center is close to the polar residues Asn49 and His87 (Figures S70E and S71). We investigated whether the flexibility of the metal complexes is restricted upon encapsulation by performing $\mathrm{MD}$ simulations for $\mathbf{1}^{\mathrm{Bio}}$ and $\mathbf{2}^{\mathrm{Bio}}$ in solution. In the absence of protein, both complexes have a certain flexibility. However, complex $2^{\mathrm{Bio}}$, with the longer link, is the most flexible one, as indicated by the computed root-mean square deviations (RMSD, see Figure S74). The higher flexibility of $2^{\text {Bio }}$ is also retained upon protein encapsulation (compare RMSD of $\mathbf{1}^{\text {Bio }}$ and $\mathbf{2}^{\text {Bio }}$ inside the protein, Figures S75 and S76), which allows a higher water accessibility, consistent with the water shell and $\mathbf{g}(\mathbf{r})$ analysis (Figure S73). 


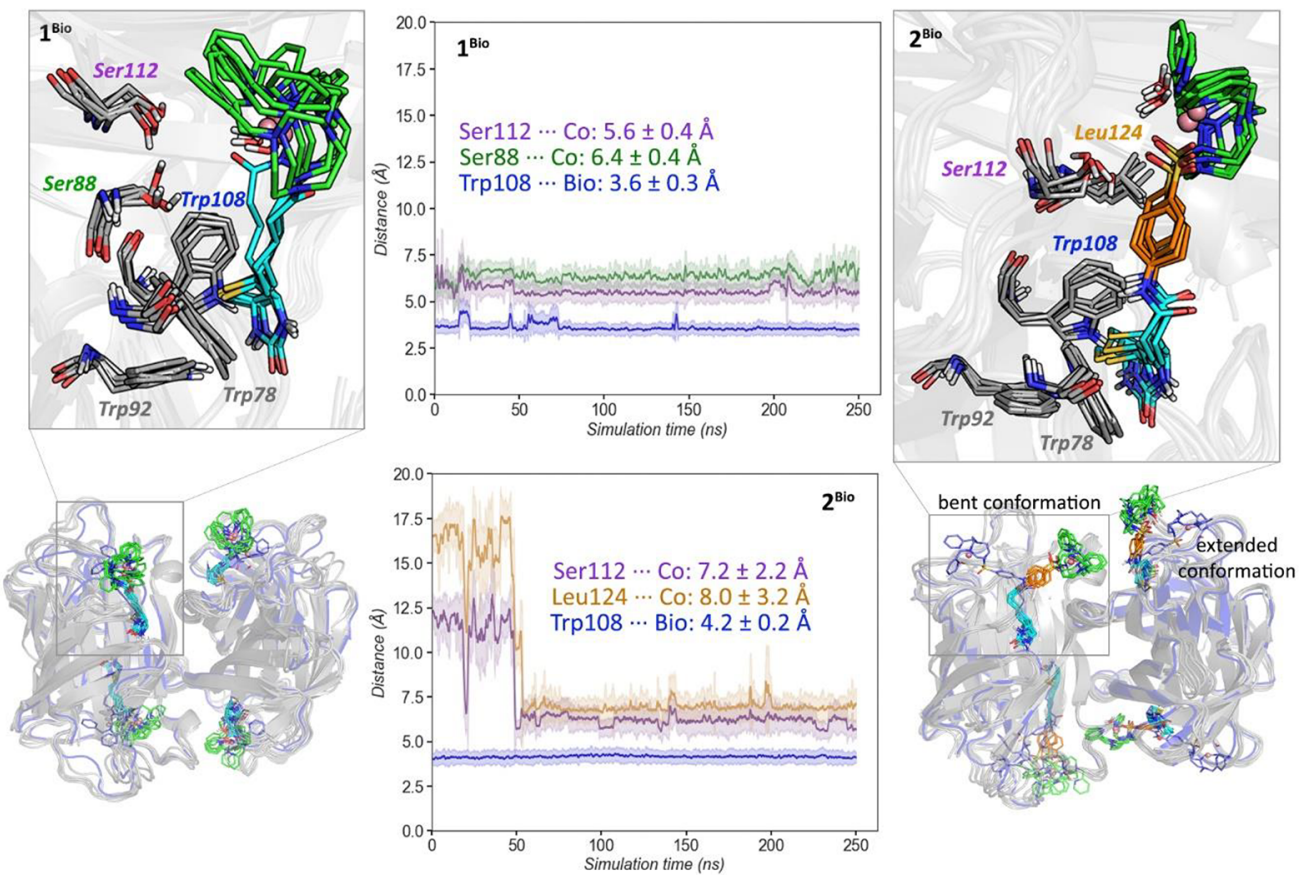

Figure 5. Overlay of representative snapshots visited along the MD simulations for $\mathbf{1}^{\text {Bio }}$ and $\mathbf{2}^{\text {Bio }}$. Conformational dynamics of the binding pockets are also shown, where the most important residues surrounding the biotin complexes are represented together with some selected distances (in Angstroms). Distances have been computed from the metal center and either the side chain of Ser112, Ser88 (oxygen atom, in purple and green, respectively), and Leu25 (terminal carbon of isobutyl side chain, orange). Trp108-biotin distance is computed between the center of mass of the indole ring of Trp108 and the tetrahydrothiophene ring of biotin (in blue). Mean distances and standard deviations are also included (in Angstroms).

\section{CONCLUSIONS}

In conclusion, we prepared new cobalt artificial metalloenzymes based on the biotin-streptavidin technology and able to reduce water to hydrogen under electro- and photochemical conditions. We found that incorporation of the cobalt catalysts into the streptavidin scaffold results in several beneficial effects, especially in the $2^{\text {Bio }}$ catalyst. It reduces the overpotential for electrocatalytic hydrogen production and increases the light-driven hydrogen production rate and turnover numbers. This work demonstrates a straightforward and successful strategy to enhance the catalytic activity for water reduction to $\mathrm{H}_{2}$. Future studies will be performed to extend such cobalt artificial metalloenzymes to various other photocatalytic chemical transformations.

\section{EXPERIMENTAL SECTION}

Materials and Reagents. Reagents and solvents were purchased from commercial sources and used as received unless otherwise stated. Triethylamine $\left(\mathrm{Et}_{3} \mathrm{~N}, \geq 99 \%\right.$ purity) and triethanolamine (TEOA, $\geq 99 \%$ purity) were purchased from Sigma-Aldrich and used without further purification. Photosensitizer $\left[\operatorname{Ir}(\right.$ bpy $\left.)(\text { ppy })_{2}\right] \mathrm{PF}_{6}\left(\mathbf{P S}_{\text {Ir }}\right)$ was synthesized according to literature procedures. ${ }^{26 a}$ Ethyl $[(3 \mathrm{a} S, 4 S, 6 \mathrm{a} R)-2$ oxo-hexahydrothieno [3,4-d]imidazole-4-yl] pentanoate

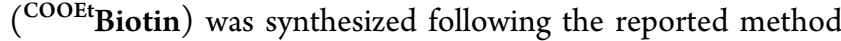
from the literature. ${ }^{31}$ Anhydrous acetonitrile was purchased from Scharlab. Water $(18.2 \mathrm{M} \mathbf{\Omega} \cdot \mathrm{cm})$ was purified with a MilliQ Millipore Gradient AIS system. All solvents were thoroughly degassed and stored under anaerobic conditions.

Physical Methods. UV-vis Spectroscopy. UV-vis spectra were acquired on a Varian Cary 50 Bio Spectrophotometer.
Gas Chromatography. Gas chromatography was carried out on a SRI instruments, model $310 \mathrm{C}$, GC using a $5 \AA$ molecular sieve column with a thermal conductivity detector and argon carrier gas.

Nuclear Magnetic Resonance. All NMR spectra were recorded in $\mathrm{CDCl}_{3}$ on a Varian 400 or $500 \mathrm{MHz}$ instrument, as noted.

Circular Dichroism. Spectra measurements were carried out on an Applied Photophysics Chirascan Circular Dichroism spectrometer equipped with a photomultiplier detector, dualpolarizing prism design monochromator, photoelastic modulator (PEM), and $150 \mathrm{~W}$ xenon light source. An average of 3 scans per sample were measured.

$X$-ray Diffraction. Crystals of $\mathbf{1}^{\text {Amide }}$ were grown by slow diffusion of $\mathrm{Et}_{2} \mathrm{O}$ to a $\mathrm{CH}_{2} \mathrm{Cl}_{2}$ solution of the complex. The crystals for these samples were selected using a Zeiss stereomicroscope using polarized light and prepared under inert conditions immersed in perfluoropolyether as protecting oil for manipulation. Crystal structure determinations for $\mathbf{1}^{\text {Amide }}$ were carried out using a Apex DUO Kappa 4-axis goniometer equipped with an APPEX $24 \mathrm{~K}$ CCD area detector, a Microfocus Source E025 IuS using Mo K $\alpha$ radiation, Quazar MX multilayer optics as monochromator, and an Oxford Cryosystems low-temperature device Cryostream 700 plus $\left(T=-173{ }^{\circ} \mathrm{C}\right)$. On the Bruker device, the following programs were used: Data collection APEX- $2,{ }^{32}$ data reduction Bruker Saint ${ }^{33}$ V/.60A, and absorption correction SADABS $^{34}$ or TWINABS. ${ }^{35}$ The crystal structure solution was achieved using the computer program SHELXT. ${ }^{36}$ Visualization was performed with the program SHELXle. ${ }^{37}$ Missing atoms were subsequently located from difference Fourier synthesis and added to the atom list. Least-squares refinement on $F^{2}$ using all measured intensities was carried out using the 
program SHELXL 2015. ${ }^{38}$ All non-hydrogen atoms were refined including anisotropic displacement parameters.

Cyclic Voltammetry. Electrochemical experiments were carried out on a $\mathrm{CH}$ instruments $1242 \mathrm{~B}$ potentiostat and with a VSP potentiostat from Bio-Logic, equipped with the EC-Lab software. The experiments were performed under inert (Ar) atmosphere in a custom double-wall jacketed singlecompartment cell. For all electrochemical measurements, a three-electrode system was used: a $3 \mathrm{~mm}$ diameter glassy carbon working electrode with a surface area of $0.28 \mathrm{~cm}^{2}$, a platinum mesh counter electrode, and a saturated calomel reference electrode, unless otherwise specified. Working electrodes were polished with $1 \mu \mathrm{M}$ alumina for $5 \mathrm{~min}$, followed by $10 \mathrm{~min}$ of sonication, prior to use. Cyclic voltammetry was carried out on samples prepared in 100 $\mathrm{mM}$ citrate and $25 \mathrm{mM} \mathrm{NaCl}$ buffer of desired $\mathrm{pH}$ (3.5, 4.0, $4.5,5.0,5.5$, and 6.0$)$; scans were performed at a $100 \mathrm{mV} \cdot \mathrm{s}^{-1}$ scan rate. All potentials are quoted versus SCE. All electrolyte solutions were degassed by freeze and pump techniques. Samples were prepared by diluting the catalyst from a stock solution $(10 \mathrm{mM})$ in water containing $5 \%$ DMSO to solubilize the catalyst. The final percentage of DMSO in the electrochemical cell was $0.5 \%$. Electrochemical experiments Cat $^{\text {Bio }} \mathrm{C}$ SA were done by preparing a thin film of $\mathrm{Cat}^{\mathrm{Bio}} \mathrm{C}$ SA over the glassy carbon electrodes $\left(0.28 \mathrm{~cm}^{2}\right.$ surface area) by drop casting of $10 \mu \mathrm{L}$ of a stock solution of metalloprotein of $10 \mu \mathrm{M}$ and drying, otherwise indicated. After drying, electrochemical measurements were performed by directly submerging the glassy carbon electrode into the solution.

Electron Paramagnetic Resonance. An EMX Micro Xband EPR spectrometer from Bruker was used to collect data on $0.35 \mathrm{mM}$ solution samples in a mixture of aqueous buffer and $\mathrm{MeCN}$ (7:3, buffer $=$ Tris $\cdot \mathrm{HCl} 100 \mathrm{mM}$, pH 7.5) using a finger Dewar at $77 \mathrm{~K}$ and $\mathrm{He}$ cryostat from Oxford Instruments at 50 and $15 \mathrm{~K}$. Data was acquired in perpendicular mode with a modulation frequency of $100 \mathrm{KHz}$, a modulation amplitude of $10 \mathrm{G}$, a $10.24 \mathrm{~ms}$ time constant, and $19.02 \mathrm{~ms}$ conversion time with a microwave power was $0.1851 \mathrm{~mW}$. Spectra were simulated using the EasySpin software package. ${ }^{39}$

$X$-ray Absorption Spectroscopy. All NM Samples were recorded as $0.35 \mathrm{mM}$ solutions in a mixture of aqueous buffer and $\mathrm{MeCN}$ (7:3, buffer = Tris. $\mathrm{HCl} 100 \mathrm{mM}, \mathrm{pH}$ 7.5) at the SOLEIL synchrotron $(2.75 \mathrm{GeV}, 400 \mathrm{~mA}$ storage ring) SAMBA Beamline equipped with a helium cryostat $(20 \mathrm{~K})$ and using a $\mathrm{Si}(220)$ double-crystal monochromator together with a 36 channel Ge detector. Data calibration and normalization was carried out using the Athena software package. ${ }^{40}$ Energies were calibrated to the first inflection point of Co foil spectra set at $7709.5 \mathrm{eV}$. A linear pre-edge function and a quadratic polynomial for the postedge were used for background subtraction and normalization of the edge jump.

Photoinduced $\mathrm{H}_{2}$ Evolution. Photoinduced $\mathrm{H}_{2}$ production irradiation was performed using a $450 \mathrm{~W}$ xenon lamp with a $400 \mathrm{~nm}$ cutoff filter, irradiating at a constant $1100 \mathrm{~W} / \mathrm{m}^{2}$ throughout the experiment. For each experiment, $400 \mu \mathrm{L}$ of a reaction mixture containing all of the reagents was added to an airtight $1 \mathrm{~mm}$ cuvette and degassed extensively with argon prior to illumination. During irradiation time course $100 \mu \mathrm{L}$ samples of the headspace were removed with a gastight syringe and injected directly for analysis by GC. A GC calibration curve was obtained by injecting various volumes of a $1 \% \mathrm{H}_{2}$, $99 \% \mathrm{~N}_{2}$ gas mixture. The $\mathrm{pH}$ of the buffer solutions was measured and adjusted (if needed) after addition of TEOA by addition $\mathrm{NaOH}$ or $\mathrm{HCl}$.

Theoretical Calculations. DFT Calculations. We studied the coordination ability of the biotinated ligands ${ }^{\text {Bio }} \mathbf{P y}_{2}$ tacn and ${ }^{\text {Bio-SP }} \mathbf{P y}_{2}$ tacn to the metal center and the possibility of binding the biotin fragment to the metal center in complexes $\mathbf{1}^{\text {Bio }}$ and $2^{\text {Bio }}$ computationally by density functional theory (DFT) using the Gaussian09 program. ${ }^{41}$ Geometry optimizations were performed in the unrestricted spin formalism, with the B3LYP hybrid exchange-correlation functional ${ }^{42}$ and the standard $6-31+\mathrm{G}^{* *} 6 \mathrm{~d}$ basis set for all atoms. An extra quadratic convergent SCF step was added when the first-order SCF did not converge ("scf = xqc" keyword). The solvation effect of acetonitrile was introduced in geometry optimizations and energy through the IEFPCM-SMD polarizable continuum model. ${ }^{43}$ Dispersion effects were also included using the Grimme $\mathrm{D}_{3}$ correction. ${ }^{44}$ The geometries have been edited with the Chemcraft program. ${ }^{45}$ The located stationary points were characterized by analytical frequency calculations at the same level of theory as geometry optimizations. Gibbs energy values $(G)$ were obtained by including thermal, solvation, and Grimme corrections to the potential energy computed with the $6-31+\mathrm{G}^{* *} 6 \mathrm{~d}$ basis set on equilibrium geometries.

Molecular Dynamics Simulations. MD simulations in explicit water were performed using the AMBER 16 package ${ }^{46}$ on our in-house GPU cluster Galatea. $\mathbf{1}^{\text {Bio }}$ and $2^{\text {Bio }}$ parameters for the MD simulations were generated within the antechamber module of AMBER 16 using the general AMBER force field (GAFF). ${ }^{47}$ We used the bonded model for the Co (quadruplet state as the lowest in energy) and ligand moiety; in particular, we used the Seminario method approach to obtain the metal parameters needed for the simulation as implemented in Prof. Ryde's program. ${ }^{48}$ The optimization, frequencies, and partial charge were set to fit the electrostatic potential generated at the UB3LYP/6-31G(d) level by the restrained electrostatic potential (RESP) model using Gaussian 09. The charges were calculated according to the Merz-Singh-Kollman scheme. We docked $\mathbf{1}^{\mathrm{Bio}}$ and $\mathbf{2}^{\mathrm{Bio}}$ complexes in the biotin pocket using the pair-fitting tool in Pymol (http://www.pymol.org) using the biotin moiety of the crystal structure (PDB 1MK5) as a reference and the optimized structure of the complex creating the tetramer enzyme. Amino acid protonation states and the data needed for the electrostatic map were set up using the Propka3.0 server (http://nbcr-222.ucsd.edu/pdb2pqr_2.0.0/ ). ${ }^{49}$ Then the enzyme was solvated in a pre-equilibrated truncated cuboid box with a $10 \AA$ buffer of TIP $3 \mathrm{P}^{50}$ water molecules using the AMBER16 leap module, resulting in the addition of ca. 9000 solvent molecules. The systems were neutralized by addition of explicit counterions $\left(\mathrm{Na}^{+}\right.$and $\left.\mathrm{Cl}^{-}\right)$. All subsequent calculations were carried out using the widely tested Stony Brook modification of the Amber 99 force field (ff14SB) ${ }^{51}$ The structure used was $1 \mathrm{MK} 5$ from the protein data bank (PDB).

A two-stage geometry optimization was performed. The first stage minimizes the positions of solvent molecules and ions imposing positional restraints on solute by a harmonic potential with a force constant of $500 \mathrm{kcal} \mathrm{mol}^{-1} \AA^{-2}$, and the second stage is an unrestrained minimization of all of the atoms in the simulation cell. The systems are gently heated using six 50 ps steps, incrementing the temperature $50 \mathrm{~K}$ each step $(0-300 \mathrm{~K})$ under constant volume and periodic boundary conditions. Water molecules were treated with the SHAKE algorithm such that the angle between the hydrogen atoms is 
kept fixed. Long-range electrostatic effects were modeled using the particle-mesh-Ewald method. ${ }^{52}$

A $8 \AA$ cutoff was applied to Lennard-Jones and electrostatic interactions. Harmonic restraints of $10 \mathrm{kcal} \cdot \mathrm{mol}^{-1}$ were applied to the solute, and the Langevin equilibration scheme was used to control and equalize the temperature. The time step was kept at 1 fs during the heating stages, allowing potential inhomogeneities to self-adjust. Each system was then equilibrated without restrains for $2 \mathrm{~ns}$ with a 2 fs time step at a constant pressure of $1 \mathrm{~atm}$ and temperature of $300 \mathrm{~K}$. After the systems were equilibrated in the NPT ensemble, 3 independent $250 \mathrm{~ns} \mathrm{MD}$ simulations for $\mathbf{1}^{\text {Bio }}$ and $\mathbf{2}^{\text {Bio }}$ (i.e., $750 \mu \mathrm{s}$ accumulated) were performed under the NVT ensemble and periodic-boundary conditions.

\section{ASSOCIATED CONTENT}

\section{S Supporting Information}

The Supporting Information is available free of charge on the ACS Publications website at DOI: 10.1021/acscatal.8b04981.

Synthesis and characterization of ligands, catalysts, and SA adducts; determination of electro- and photocatalytic performance; DFT and molecular dynamic simulations (PDF)

\section{AUTHOR INFORMATION}

\section{Corresponding Authors}

*E-mail: gghirlanda@asu.edu

*E-mail: jlloret@iciq.es

\section{ORCID}

Arnau Call: 0000-0003-0970-7195

Sílvia Osuna: 0000-0003-3657-6469

Julio Lloret-Fillol: 0000-0002-4240-9512

\section{Author Contributions}

${ }^{\ddagger}$ A.C. and C.C.: These authors ontributed equally.

\section{Notes}

The authors declare no competing financial interest.

\section{ACKNOWLEDGMENTS}

We thank the European Commission for the ERC-CG-2014648304 (J.Ll.-F) and ERC-2015-StG-679001 (S.O) projects. The Spanish Ministry of Science is acknowledged for a FPU fellowship to A.C. (AP2012-6436) and C.C. and the Generalitat de Catalunya for a Ph.D. fellowship to A.R.R. (2015-FI-B-00165). We also thank Catexel for a generous gift of tritosyl-1,4,7-triazacyclononane. Financial support from the ICIQ Foundation and CELLEX Foundation through the CELLEX-ICIQ high-throughput experimentation platform and the Starting Career Program is gratefully acknowledged. We also thank the CERCA Programme (Generalitat de Catalunya) for financial support and MINECO (Severo Ochoa Excellence Accreditation 2014-2018; SEV-2013-0319) and MINECO project CTQ2016-80038-R. S.O. thanks the Spanish MINECO CTQ2016-80038-R, Ramón y Cajal contract (RYC-201416846), the European Community for CIG project (PCIG14GA-2013-630978). This work was supported in part by NSF award 1508301 to G.G. We acknowledge SOLEIL and DIAMOND for provision of synchrotron radiation facilities, and we thank Dr. Gautier Landrot for assistance in using beamline SAMBA. We are grateful for the computer resources, technical expertise, and assistance provided by the Barcelona
Supercomputing Center-Centro Nacional de Supercomputación.

\section{REFERENCES}

(1) (a) Barber, J.; Tran, P. D. From Natural to Artificial Photosynthesis. J. R. Soc., Interface 2013, 10, 20120984. (b) Lewis, N. S.; Nocera, D. G. Powering the Planet: Chemical Challenges in Solar Energy Utilization. Proc. Natl. Acad. Sci. U. S. A. 2006, 103, 15729-15735.

(2) (a) McKone, J. R.; Marinescu, S. C.; Brunschwig, B. S.; Winkler, J. R.; Gray, H. B. Earth-abundant Hydrogen Evolution Electrocatalysts. Chem. Sci. 2014, 5, 865-878. (b) Du, P.; Eisenberg, R. Catalysts Made of Earth-abundant Elements (Co, Ni, Fe) for Water Splitting: Recent Progress and Future Challenges. Energy Environ. Sci. 2012, 5, 6012-6021. (c) Artero, V.; Chavarot-Kerlidou, M.; Fontecave, M. Splitting Water with Cobalt. Angew. Chem., Int. Ed. 2011, 50, 7238-7266. (d) Le Goff, A.; Artero, V.; Jousselme, B.; Tran, P. D.; Guillet, N.; Metaye, R.; Fihri, A.; Palacin, S.; Fontecave, M. From Hydrogenases to Noble Metal-free Catalytic Nanomaterials for $\mathrm{H}_{2}$ Production and Uptake. Science 2009, 326, 1384-1387.

(3) (a) Lubitz, W.; Ogata, H.; Rudiger, O.; Reijerse, E. Hydrogenases. Chem. Rev. 2014, 114, 4081-4148. (b) Simmons, T. R.; Berggren, G.; Bacchi, M.; Fontecave, M.; Artero, V. Mimicking Hydrogenases: From Biomimetics to Artificial Enzymes. Coord. Chem. Rev. 2014, 270-271, 127-150. (c) Tard, C.; Pickett, C. J. Structural and Functional Analogues of the Active Sites of the [Fe]-, [NiFe]-, and $[\mathrm{FeFe}]-$ Hydrogenases. Chem. Rev. 2009, 109, 2245-2274.

(4) (a) Mulder, D. W.; Shepard, E. M.; Meuser, J. E.; Joshi, N.; King, P. W.; Posewitz, M. C.; Broderick, J. B.; Peters, J. W. Insights into $[\mathrm{FeFe}]$-hydrogenase Structure, Mechanism, and Maturation. Structure 2011, 19, 1038-1052. (b) Knörzer, P.; Silakov, A.; Foster, C. E.; Armstrong, F. A.; Lubitz, W.; Happe, T. Importance of the Protein Framework for Catalytic Activity of [FeFe]-hydrogenases. J. Biol. Chem. 2012, 287, 1489-1499. (c) Berggren, G.; Adamska, A.; Lambertz, C.; Simmons, T. R.; Esselborn, J.; Atta, M.; Gambarelli, S.; Mouesca, J. M.; Reijerse, E.; Lubitz, W.; Happe, T.; Artero, V.; Fontecave, M. Aiomimetic Assembly and Activation of $[\mathrm{FeFe}]$ hydrogenases. Nature 2013, 499, 66-69. (d) Esselborn, J.; Lambertz, C.; Adamska-Venkatesh, A.; Simmons, T.; Berggren, G.; Noth, J.; Siebel, J.; Hemschemeier, A.; Artero, V.; Reijerse, E.; Fontecave, M.; Lubitz, W.; Happe, T. Spontaneous Activation of [FeFe]-hydrogenases by an Inorganic [2Fe] Active Site Mimic. Nat. Chem. Biol. 2013, 9, 607-609.

(5) (a) Zee, D. Z.; Chantarojsiri, T.; Long, J. R.; Chang, C. J. Metalpolypyridyl Catalysts for Electro- and Photochemical Reduction of Water to Hydrogen. Acc. Chem. Res. 2015, 48, 2027-2036. (b) Queyriaux, N.; Jane, R. T.; Massin, J.; Artero, V.; ChavarotKerlidou, M. Recent Developments in Hydrogen Evolving Molecular Cobalt(II)-polypyridyl Catalysts. Coord. Chem. Rev. 2015, 304-305, $3-19$.

(6) (a) Jian, J. X.; Liu, Q.; Li, Z. J.; Wang, F.; Li, X. B.; Li, C. B.; Liu, B.; Meng, Q. Y.; Chen, B.; Feng, K.; Tung, C. H.; Wu, L. Z. Chitosan Confinement Enhances Hydrogen Photogeneration from a Mimic of the Diiron Subsite of [FeFe]-hydrogenase. Nat. Commun. 2013, 4, 19. (b) Singleton, M. L.; Reibenspies, J. H.; Darensbourg, M. Y. A Cyclodextrin Host/Guest Approach to a Hydrogenase Active Site Biomimetic Cavity. J. Am. Chem. Soc. 2010, 132, 8870-8871.

(7) (a) Orain, C.; Quentel, F.; Gloaguen, F. Photocatalytic Hydrogen Production Using Models of the Iron-iron Hydrogenase Active Site Dispersed in Micellar Solution. ChemSusChem 2014, 7, 638-643. (b) Pullen, S.; Fei, H.; Orthaber, A.; Cohen, S. M.; Ott, S. Enhanced Photochemical Hydrogen Production by a Molecular Diiron Catalyst Incorporated into a Metal-organic Framework. J. Am. Chem. Soc. 2013, 135, 16997-17003. (c) Yu, T.; Zeng, Y.; Chen, J.; Li, Y. Y.; Yang, G.; Li, Y. Exceptional Dendrimer-based Mimics of Diiron Hydrogenase for the Photochemical Production of Hydrogen. Angew. Chem., Int. Ed. 2013, 52, 5631-5635.

(8) (a) Faiella, M.; Roy, A.; Sommer, D.; Ghirlanda, G. De NovoDesign of Functional Proteins: Toward Artificial Hydrogenases. 
Biopolymers 2013, 100, 558-571. (b) Bos, J.; Browne, W. R.; Driessen, A. J. M.; Roelfes, G. Supramolecular Assembly of Artificial Metalloenzymes Based on the Dimeric Protein LmrR as Promiscuous Scaffold. J. Am. Chem. Soc. 2015, 137, 9796-9799.

(9) (a) Soltau, S. R.; Niklas, J.; Dahlberg, P. D.; Poluektov, O. G.; Tiede, D. M.; Mulfort, K. L.; Utschig, L. M. Aqueous Light Driven Hydrogen Production by a $\mathrm{Ru}$-ferredoxin-Co Biohybrid. Chem. Commun. 2015, 51, 10628-10631. (b) Onoda, A.; Kihara, Y.; Fukumoto, K.; Sano, Y.; Hayashi, T. Photoinduced Hydrogen Evolution Catalyzed by a Synthetic Diiron Dithiolate Complex Embedded within a Protein Matrix. ACS Catal. 2014, 4, 2645-2648. (c) Bacchi, M.; Berggren, G.; Niklas, J.; Veinberg, E.; Mara, M. W.; Shelby, M. L.; Poluektov, O. G.; Chen, L. X.; Tiede, D. M.; Cavazza, C.; Field, M. J.; Fontecave, M.; Artero, V. Cobaloxime-based Artificial Hydrogenases. Inorg. Chem. 2014, 53, 8071-8082. (d) Silver, S. C.; Niklas, J.; Du, P.; Poluektov, O. G.; Tiede, D. M.; Utschig, L. M. Protein Delivery of a Ni Catalyst to Photosystem I for Light-driven Hydrogen Production. J. Am. Chem. Soc. 2013, 135, 13246-13249. (e) Berggren, G.; Adamska, A.; Lambertz, C.; Simmons, T. R.; Esselborn, J.; Atta, M.; Gambarelli, S.; Mouesca, J. M.; Reijerse, E.; Lubitz, W.; Happe, T.; Artero, V.; Fontecave, M. Biomimetic Assembly and Activation of $[\mathrm{FeFe}]$-hydrogenases. Nature 2013, 499, 66-69. (f) Utschig, L. M.; Silver, S. C.; Mulfort, K. L.; Tiede, D. M. Nature-driven Photochemistry for Catalytic Solar Hydrogen Production: a Photosystem I-transition Metal Catalyst Hybrid. J. Am. Chem. Soc. 2011, 133, 16334-16337.

(10) (a) Kandemir, B.; Chakraborty, S.; Guo, Y.; Bren, K. L. Semisynthetic and Biomolecular Hydrogen Evolution Catalysts. Inorg. Chem. 2016, 55, 467-477. (b) Slater, J. W.; Shafaat, H. S. Nickelsubstituted Rubredoxin as a Minimal Enzyme Model for Hydrogenase. J. Phys. Chem. Lett. 2015, 6, 3731-3736. (c) Sommer, D. J.; Vaughn, M. D.; Clark, B. C.; Tomlin, J.; Roy, A.; Ghirlanda, G. Reengineering Cyt $\mathrm{b}$ for Hydrogen Production: A facile Route to Artificial Hydrogenases. Biochim. Biophys. Acta, Bioenerg. 2016, 1857, 598-603. (d) Sommer, D. J.; Vaughn, M. D.; Ghirlanda, G. Protein Secondary-shell Interactions Enhance the Photoinduced Hydrogen Production of Cobalt Protoporphyrin IX. Chem. Commun. 2014, 50, 15852-15855. (e) Kleingardner, J. G.; Kandemir, B.; Bren, K. L. Hydrogen Evolution from Neutral Water under Aerobic Conditions Catalyzed by Cobalt Microperoxidase-11. J. Am. Chem. Soc. 2014, 136, 4-7. (f) Saint-Martin, P.; Lespinat, P. A.; Fauque, G.; Berlier, Y.; Legall, J.; Moura, I.; Teixeira, M.; Xavier, A. V.; Moura, J. J. G. Hydrogen Production and Deuterium-proton Exchange Reactions Catalyzed by Desulfovibrio Nickel(II)-substituted Rubredoxins. Proc. Natl. Acad. Sci. U. S. A. 1988, 85, 9378-9380.

(11) Weber, P. C.; Ohlendorf, D. H.; Wendoloski, J. J.; Salemme, F. R. Structural Origins of High-affinity Biotin Binding to Streptavidin. Science 1989, 243, 85-88.

(12) Wilson, M. E.; Whitesides, G. M. Conversion of a Protein to a Homogeneous Asymmetric Hydrogenation Catalyst by Site-specific Modification with a Diphosphinerhodium(I) Moiety. J. Am. Chem. Soc. 1978, 100, 306-307.

(13) (a) Liang, A. D.; Serrano-Plana, J.; Peterson, R. L.; Ward, T. R. Artificial Metalloenzymes Based on the Biotin-Streptavidin Technology: Enzymatic Cascades and Directed Evolution. Acc. Chem. Res. 2019, 52, 585. (b) Schwizer, F.; Okamoto, Y.; Heinisch, T.; Gu, Y.; Pellizzoni, M. M.; Lebrun, V.; Reuter, R.; Kohler, V.; Lewis, J. C.; Ward, T. R. Artificial Metalloenzymes: Reaction Scope and Optimization Strategies. Chem. Rev. 2018, 118, 142-231. (c) Heinisch, T.; Ward, T. R. Artificial Metalloenzymes Based on the BiotinStreptavidin Technology: Challenges and Opportunities. Acc. Chem. Res. 2016, 49, 1711-1721. (d) Chatterjee, A.; Mallin, H.; Klehr, J.; Vallapurackal, J.; Finke, A. D.; Vera, L.; Marsh, M.; Ward, T. R. An Enantioselective Artificial Suzukiase Based on the Biotin-streptavidin Technology. Chem. Sci. 2016, 7, 673-677. (e) Dundas, C. M.; Demonte, D.; Park, S. Streptavidin-biotin Technology: Improvements and Innovations in Chemical and Biological Applications. Appl. Microbiol. Biotechnol. 2013, 97, 9343-9353. (f) Ward, T. R. Artificial Metalloenzymes Based on the Biotin-Avidin Technology: Enantiose- lective Catalysis and Beyond. Acc. Chem. Res. 2011, 44, 47-57. (g) Letondor, C.; Ward, T. R. Artificial Metalloenzymes for Enantioselective Catalysis: Recent Advances. ChemBioChem 2006, 7, $1845-1852$.

(14) Keller, S. G.; Probst, B.; Heinisch, T.; Alberto, R.; Ward, T. R. Photo-driven Hydrogen Evolution by an Artificial Hydrogenase Utilizing the Biotin-Streptavidin Technology. Helv. Chim. Acta 2018, 101, e1800036.

(15) (a) Call, A.; Codolà, Z.; Acuña-Parés, F.; Lloret-Fillol, J. Photoand Electrocatalytic $\mathrm{H}_{2}$ Production by New First-row Transitionmetal Complexes Based on an Aminopyridine Pentadentate Ligand. Chem. - Eur. J. 2014, 20, 6171-6183. (b) Call, A.; Franco, F.; Kandoth, N.; Fernández, S.; González-Béjar, M.; Pérez-Prieto, J.; Luis, J. M.; Lloret-Fillol, J. Understanding Light-driven $\mathrm{H}_{2}$ Evolution through the Electronic Tuning of Aminopyridine Cobalt Complexes. Chem. Sci. 2018, 9, 2609-2619.

(16) Skander, M.; Humbert, N.; Collot, J.; Gradinaru, J.; Klein, G.; Loosli, A.; Sauser, J.; Zocchi, A.; Gilardoni, F.; Ward, T. R. Artificial Metalloenzymes: (Strept)avidin as Host for Enantioselective Hydrogenation by Achiral Biotinylated Rhodium-diphosphine Complexes. J. Am. Chem. Soc. 2004, 126, 14411-14418.

(17) Wilson, M. E.; Nuzzo, R. G.; Whitesides, G. M. Bis(2diphenylphosphinoethyl)amine. A flexible Synthesis of Functionalized Chelating Diphosphines. J. Am. Chem. Soc. 1978, 100, 2269-2270.

(18) (a) Planas, O.; Whiteoak, C. J.; Martin-Diaconescu, V.; Gamba, I.; Luis, J. M.; Parella, T.; Company, A.; Ribas, X. Isolation of Key Organometallic Aryl-Co(III) Intermediates in Cobalt-Catalyzed $\mathrm{C}\left(\mathrm{sp}^{2}\right)-\mathrm{H}$ Functionalizations and New Insights into Alkyne Annulation Reaction Mechanisms. J. Am. Chem. Soc. 2016, 138, 14388-14397. (b) Planas, O.; Roldán-Gómez, S.; Martin-Diaconescu, V.; Luis, J. M.; Company, A.; Ribas, X. Mechanistic Insights into the $\mathrm{S}_{\mathrm{N}}$ 2-type Reactivity of Aryl-Co(III) Masked-carbenes for C-C Bond Forming Transformations. Chem. Sci. 2018, 9, 5736-5746. (c) Sarangi, R.; Cho, J.; Nam, W.; Solomon, E. I. XAS and DFT Investigation of Mononuclear Cobalt(III) Peroxo Complexes: Electronic Control of the Geometric Structure in $\mathrm{CoO}_{2}$ versus $\mathrm{NiO}_{2}$ Systems. Inorg. Chem. 2011, 50, 614-620. (d) Fujita, E.; Furenlid, L. R.; Renner, M. W. Direct XANES Evidence for Charge Transfer in $\mathrm{Co}-\mathrm{CO}_{2}$ Complexes. J. Am. Chem. Soc. 1997, 119, 4549-4550.

(19) Nishida, Y.; Ida, K.; Kida, S. Investigation on Low-spin Cobalt(II) Complexes.X. [1] An ESR Study on Six-coordinate Complexes. Inorg. Chim. Acta 1980, 38, 113-116.

(20) (a) The overpotential is defined as the difference between the applied potential and the thermodynamic potential for the reduction of protons at given conditions. The overpotential is defined as the difference between the applied potential and the thermodinamic potential for the reduction of protons at given conditions. (b) The thermodyinamic potential for the electrocatalytic water reduction to $\mathrm{H}_{2}$ at given $\mathrm{pH}\left(\mathrm{SCE}, 1\right.$ atm of $\left.\mathrm{H}_{2}\right)$ is $E(\mathrm{pH})=-0.241 \mathrm{~V}-0.059 \mathrm{~V} \times$ $\mathrm{pH}$. The thermodynamic potential for the electrocatalytic water reduction to $\mathrm{H}_{2}$ at given $\mathrm{pH}\left(\mathrm{SCE}, 1 \mathrm{~atm}\right.$ of $\left.\mathrm{H}_{2}\right)$ is $E(\mathrm{pH})=-0.241 \mathrm{~V}$ $-0.059 \mathrm{~V} \times \mathrm{pH}$.

(21) (a) McCrory, C. C.; Uyeda, C.; Peters, J. C. Electrocatalytic Hydrogen Evolution in Acidic Water with Molecular Cobalt Tetraazamacrocycles. J. Am. Chem. Soc. 2012, 134, 3164-3170. (b) Sun, Y.; Bigi, J. P.; Piro, N. A.; Tang, M. L.; Long, J. R.; Chang, C. J. Molecular Cobalt Pentapyridine Catalysts for Generating Hydrogen from Water. J. Am. Chem. Soc. 2011, 133, 9212-9215. (c) McNamara, W. R.; Han, Z.; Yin, C.-J. M.; Brennessel, W. W.; Holland, P. L.; Eisenberg, R. Cobalt-dithiolene Complexes for the Photocatalytic and Electrocatalytic Reduction of Protons in Aqueous Solutions. Proc. Natl. Acad. Sci. U. S. A. 2012, 109, 15594-15599. (d) Abe, T.; Kaneko, M. pH-dependent Electrocatalysis for Proton Reduction by $\operatorname{Bis}\left(2,2^{\prime}: 6^{\prime}, 2^{\prime \prime}\right.$-terpyridine) Cobalt(II) Complex Embedded in Nafion ${ }^{\circledR}$ Membrane. J. Mol. Catal. A: Chem. 2001, 169, 177-183. (e) Slater, J. W.; Marguet, S. C.; Monaco, H. A.; Shafaat, H. S. Going beyond Structure: Nickel-Substituted Rubredoxin as a Mechanistic Model for the [NiFe] Hydrogenases. J. Am. Chem. Soc. 2018, 140, 10250-10262. 
(22) (a) Slattery, S. J.; Blaho, J. K.; Lehnes, J.; Goldsby, K. A. pHDependent Metal-based Redox Couples as Models for Protoncoupled Electron Transfer Reactions. Coord. Chem. Rev. 1998, 174, 391-416. (b) Save'ant, J.-M. Elements of Molecular and Biomolecular Electrochemistry: An Electrochemical Approach to Electron Transfer Chemistry; Wiley-Interscience: Hoboken, NJ, 2006. (c) Horvath, S.; Fernandez, L. E.; Appel, A. M.; Hammes-Schiffer, S. pH-dependent Reduction Potentials and Proton-coupled Electron Transfer Mechanisms in Hydrogen-producing Nickel Molecular Electrocatalysts. Inorg. Chem. 2013, 52, 3643-3652.

(23) Anxolabéhère-Mallart, E.; Costentin, C.; Fournier, M.; Nowak, S.; Robert, M.; Saveant, J. M. Boron-capped Tris(glyoximato) Cobalt Clathrochelate as a Precursor for the Electrodeposition of Nanoparticles Catalyzing $\mathrm{H}_{2}$ Evolution in Water. J. Am. Chem. Soc. 2012, 134, 6104-6107.

(24) Bigi, J. P.; Hanna, T. E.; Harman, W. H.; Chang, A.; Chang, C. J. Electrocatalytic Reduction of Protons to Hydrogen by a Watercompatible Cobalt Polypyridyl Platform. Chem. Commun. 2010, 46, 958-960.

(25) Léger, C.; Elliott, S. J.; Hoke, K. R.; Jeuken, L. J. C.; Jones, A. K.; Armstrong, F. A. Enzyme Electrokinetics: using Protein Film Voltammetry to Investigate Redox Enzymes and their Mechanisms. Biochemistry 2003, 42, 8653-8662.

(26) (a) Cline, E. D.; Adamson, S. E.; Bernhard, S. Homogeneous Catalytic System for Photoinduced Hydrogen Production Utilizing Iridium and Rhodium Complexes. Inorg. Chem. 2008, 47, 1037810388. (b) Curtin, P. N.; Tinker, L. L.; Burgess, C. M.; Cline, E. D.; Bernhard, S. Structure-activity Correlations among Iridium(III) Photosensitizers in a Robust Water-reducing System. Inorg. Chem. 2009, 48, 10498-10506. (c) Hanss, D.; Freys, J. C.; Bernardinelli, G.; Wenger, O. S. Cyclometalated Iridium(III) Complexes as Photosensitizers for Long-range Electron Transfer: Occurrence of a Coulomb Barrier. Eur. J. Inorg. Chem. 2009, 2009, 4850-4859. (d) Ladouceur, S.; Fortin, D.; Zysman-Colman, E. Role of Substitution on the Photophysical Properties of 5,5'-diaryl-2,2'bipyridine $\left(\mathrm{bpy}^{*}\right)$ in $\left[\operatorname{Ir}(\mathrm{ppy})_{2}\left(\mathrm{bpy}^{*}\right)\right] \mathrm{PF}_{6}$ Complexes: a Combined Experimental and Theoretical Study. Inorg. Chem. 2010, 49, 56255641.

(27) Simond, M. R.; Ballerat-Busserolles, K.; Coulier, Y.; Rodier, L.; Coxam, J. Y. Dissociation Constants of Protonated Amines in Water at Temperatures from 293.15 to 343.15 K. J. Solution Chem. 2012, 41, $130-142$.

(28) Natali, M. Elucidating the Key Role of $\mathrm{pH}$ on Light-Driven Hydrogen Evolution by a Molecular Cobalt Catalyst. ACS Catal. 2017, 7, 1330-1339.

(29) Han, Z.; McNamara, W. R.; Eum, M. S.; Holland, P. L.; Eisenberg, R. A nickel thiolate catalyst for the long-lived photocatalytic production of hydrogen in a noble-metal-free system. Angew. Chem., Int. Ed. 2012, 51, 1667-1670.

(30) (a) Stayton, P. S.; Freitag, S.; Klumb, L. A.; Chilkoti, A.; Chu, V.; Penzotti, J. E.; To, R.; Hyre, D.; Le Trong, I.; Lybrand, T. P.; Stenkamp, R. E. Streptavidin-biotin Binding Energetics. Biomol. Eng. 1999, 16, 39-44. (b) DeChancie, J.; Houk, K. N. The Origins of Femtomolar Protein-ligand Binding: Hydrogen-bond Cooperativity and Desolvation Energetics in the Biotin-(Strept)avidin Binding Site. J. Am. Chem. Soc. 2007, 129, 5419-5429. (c) The structure used was taken from the protein data bank (PDB); 1MK5.

(31) Schiller, T. L.; Keddie, D. J.; Blakey, I.; Fredericks, P. M. Surface-enhanced Raman Encoded Polymer Stabilized Gold Nanoparticles: Demonstration of Potential for Use in Bioassays. Eur. Polym. J. 2017, 87, 508-518.

(32) Data collection with APEX II, version v2013, 4-1; Bruker AXS Inc.: Madison, WI, 2007.

(33) Data reduction with Bruker SAINT, version V8.30c; Bruker AXS Inc.: Madison, WI, 2007.

(34) SADABS, V2012/1; Bruker AXS Inc.: Madison, WI, 2001.Blessing, R. H. An empirical correction for absorption anisotropy. Acta Crystallogr. 1995, A51, 33-38.
(35) TWINABS, Version 2012/1; Bruker AXS scaling for twinned crystals: Blessing, R. H. An empirical correction for absorption anisotropy. Acta Crystallogr., Sect. A: Found. Crystallogr. 1995, A51, $33-38$.

(36) SHELXT; V2014/4, 2014: Sheldrick, G. M. SHELXTintegrated space-group and crystal determination. Acta Crystallogr., Sect. A: Found. Adv. 2015, A71, 3-8.

(37) SHELXle: Hübschle, C. B.; Sheldrick, G. M.; Dittrich, B. ShelXle: a Qt graphical user interface for SHELXL. J. Appl. Crystallogr. 2011, 44, 1281-1284.

(38) SHELXL; SHELXL-2014/7, 2014: Sheldrick, G. M. SHELXTintegrated space-group and crystal determination. Acta Crystallogr., Sect. A: Found. Adv. 2015, A71, 3-8.

(39) Stoll, S.; Schweiger, A. EasySpin, a Comprehensive Software Package for Spectral Simulation and Analysis in EPR. J. Magn. Reson. 2006, 178, 42-55.

(40) (a) Newville, M. IFEFFIT: Interactive XAFS Analysis and FEFF Fitting. J. Synchrotron Radiat. 2001, 8, 322-324. (b) Ravel, B.; Newville, M. ATHENA, ARTEMIS, HEPHAESTUS: Data Analysis for X-ray Absorption Spectroscopy using IFEFFIT. J. Synchrotron Radiat. 2005, 12, 537-541.

(41) Gaussian 09, Revision E.01; Gaussian, Inc.: Wallingford, CT, 2009.

(42) (a) Becke, A. D. J. Chem. Phys. 1993, 98, 1372-1377. (b) Becke, A. D. J. Chem. Phys. 1993, 98, 5648. (c) Lee, C. T.; Yang, W. T.; Parr, R. G. Phys. Rev. B: Condens. Matter Mater. Phys. 1988, 37, 785.

(43) Marenich, A. V.; Cramer, C. J.; Truhlar, D. G. Universal Solvation Model Based on Solute Electron Density and on a Continuum Model of the Solvent Defined by the Bulk Dielectric Constant and Atomic Surface Tensions. J. Phys. Chem. B 2009, 113, 6378-6396.

(44) Grimme, S. Semiempirical GGA-type Density Functional Constructed with a Long-range Dispersion Correction. J. Comput. Chem. 2006, 27, 1787-1799.

(45) www.chemcraftprog.com.

(46) Case, D. A.; Darden, T. A.; Cheatham, T. E.; Simmerling, C. L.; Wang, J.; Duke, R. E.; Luo, R.; Crowley, M.; Walker, R. C.; Zhang, W.; Merz, K. M.; Wang, B.; Hayik, S.; Roitberg, A.; Seabra, G.; Kolossváry, I.; Wong, K. F.; Paesani, F.; Vanicek, J.; Wu, X.; Brozell, S. R.; Steinbrecher, T.; Gohlke, H.; Yang, L.; Tan, C.; Mongan, J.; Hornak, V.; Cui, G.; Mathews, D. H.; Seetin, M. G.; Sagui, C.; Babin, V.; Kollman, P. A. AMBER 16; University of California: San Francisco, CA, 2016.

(47) Wang, J.; Wolf, R. M.; Caldwell, J. W.; Kollman, P. A.; Case, D. A. Development and Testing of a General Amber Force Field. J. Comput. Chem. 2004, 25, 1157-1174.

(48) Hu, L.; Ryde, U. Comparison of Methods to Obtain ForceField Parameters for Metal Sites. J. Chem. Theory Comput. 2011, 7, 2452-2463.

(49) Dolinsky, T. J.; Nielsen, J. E.; McCammon, J. A.; Baker, N. A. PDB2PQR: an Automated Pipeline for the Setup of PoissonBoltzmann Electrostatics Calculations. Nucleic Acids Res. 2004, 32, W665-667.

(50) Jorgensen, W. L.; Chandrasekhar, J.; Madura, J. D.; Impey, R. W.; Klein, M. L. Comparison of Simple Potential Functions for Simulating Liquid Water. J. Chem. Phys. 1983, 79, 926-935.

(51) Wang, J.; Cieplak, P.; Kollman, P. A. How Well Does a Restrained ElectrostaticPotential (RESP) Model Perform in Calculating Conformational Energies of Organic and Biological Molecules? J. Comput. Chem. 2000, 21, 1049-1074.

(52) Darden, T.; York, D.; Pedersen, L. Particle mesh Ewald: An $\mathrm{N} \log (\mathrm{N})$ Method for Ewald Sums in Large Systems. J. Chem. Phys. 1993, 98, 10089-10092. 